\title{
The combination of Ki67, histological grade and estrogen receptor status identifies a low-risk group among 1,854 chemo-naïve women with N0/N1 primary breast cancer
}

\author{
Carina Strand ${ }^{1 *}$, Martin Bak², Signe Borgquist ${ }^{1}$, Gunilla Chebil ${ }^{3}$, Anna-Karin Falck', Marie-Louise Fjällskog ${ }^{5}$,

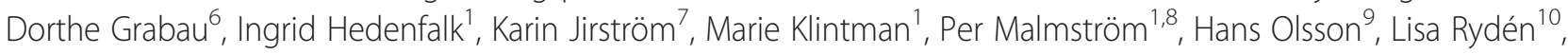 \\ Olle Stål ${ }^{11}$, Pär-Ola Bendahl ${ }^{1}$ and Mårten Fernö ${ }^{1}$
}

\begin{abstract}
Background: The aim was to confirm a previously defined prognostic index, combining a proliferation marker, histological grade, and estrogen receptor (ER) in different subsets of primary NO/N1 chemo-naïve breast cancer patients.

Methods/design: In the present study, including 1,854 patients, Ki67 was used in the index (KiGE), since it is the generally accepted proliferation marker in clinical routine. The low KiGE-group was defined as histological grade 1 patients and grade 2 patients which were ER-positive and had low Ki67 expression. All other patients made up the high KiGE-group. The KiGE-index separated patients into two groups with different prognosis. In multivariate analysis, KiGE was significantly associated with disease-free survival, when adjusted for age at diagnosis, tumor size and adjuvant endocrine treatment (hazard ratio: 3.5, 95\% confidence interval: 2.6-4.7, $P<0.0001$ ).

Discussion: We have confirmed a prognostic index based on a proliferation marker (Ki67), histological grade, and ER for identification of a low-risk group of patients with N0/N1 primary breast cancer. For this low-risk group constituting $57 \%$ of the patients, with a five-year distant disease-free survival of $92 \%$, adjuvant chemotherapy will have limited effect and may be avoided.
\end{abstract}

Keywords: Breast cancer, Chemo-naïve, Ki67, Prognostic index, Proliferation

\section{Introduction}

To predict clinical outcome and the effect of adjuvant systemic treatment in breast cancer, recommendations such as the St. Gallen breast cancer consensus guidelines (Goldhirsch et al. 2011) and the Adjuvant! Online tool (Ravdin et al. 2001) can be used. The development of array-based technologies and sequencing of the human genome (Perou et al. 2000; Sorlie et al. 2001; Paik et al. 2004; Sotiriou et al. 2006; Ivshina et al. 2006), provide additional information beyond the traditional criteria used to guide treatment decisions. This challenges the currently

\footnotetext{
* Correspondence: Carina.strand@med.lu.se

${ }^{1}$ Lund University, Division of Oncology, Department of Clinical Sciences Lund, Skåne University Hospital, Barngatan 2B, SE-221 85, Lund, Sweden Full list of author information is available at the end of the article
}

used factors, such as lymph node involvement, tumor size, age, histological grade, human epidermal growth factor receptor 2 (HER2), Ki67, and estrogen (ER) and progesterone receptor (PgR) status (Goldhirsch et al. 2011; Aebi et al. 2011; Harris et al. 2007). At the St. Gallen Consensus Meeting in 2011, Oncotype $\mathrm{DX}^{\circledR}$ was considered useful for predicting responsiveness to chemotherapy in an endocrine-responsive cohort, whereas other tests were considered not yet fully validated. Two of the most well-known gene-based assays, MammaPrint ${ }^{\circledR}$ and Oncotype $\mathrm{DX}^{\circledR}$ have, however, also been questioned with regard to their added prognostic value (Edén et al. 2004; Cuzick et al. 2011). The ongoing clinical trials, MINDACT and TAILORx, will hopefully provide more conclusive data (Rutgers et al. 2011; Zujewski \& Kamin 2008). 
High proliferation is a key feature in breast carcinogenesis and markers of proliferation have been shown to be associated to prognosis and to effect of adjuvant and palliative chemotherapy, to neoadjuvant endocrine therapy, and to prognosis after adjuvant endocrine treatment (Harris et al. 2007; Colozza et al. 2005; Beresford et al. 2006; De Azambuja et al. 2007; Goldhirsch et al. 2009; Urruticoechea et al. 2005; Hietanen et al. 1995; Amadori et al. 2008; Jones et al. 2009; Ellis et al. 2008; Viale et al. 2008). Ki67 is the marker of proliferation most widely used (Goldhirsch et al. 2011; De Azambuja et al. 2007; Urruticoechea et al. 2005; Dowsett et al. 2011; Luporsi et al. 2012), but the role of other markers, such as cyclin A (Bukholm et al. 2001; Michalides et al. 2002; Kuhling et al. 2003; Baldini et al. 2006; Ahlin et al. 2009; Strand et al. 2012) and phosphohistone H3 (Skaland et al. 2007), remains under debate. Furthermore, global gene expression analyses have shown that proliferation-associated genes seem to be among the most important for dividing patients into groups with different prognosis, especially in ER-positive and histological grade 2 breast cancers (Sotiriou et al. 2006; Ivshina et al. 2006; Teschendorff et al. 2007; Desmedt et al. 2008). In line with this, studies from our group, as well as others, have shown that single markers of proliferation (Ki67 and cyclin A) were of prognostic importance in ER-positive breast cancer and in the histological grade 2 (Strand et al. 2012; Klintman et al. 2010) and grade 1 (Aleskandarany et al. 2011) subgroups. We have previously evaluated the importance of a prognostic index based on the combination of cyclin A, histological grade, and ER (CAGE), in node-negative premenopausal breast cancer patients (Strand et al. 2012). The CAGE-index combined with HER2-status classified $53 \%$ of the women as low-risk patients with a five-year distant disease-free survival (DDFS) of 95\%. For this lowrisk group, adjuvant cytotoxic treatment will have limited efficacy and may be avoided. In the present study, we present data for Ki67. Importantly, avoiding unnecessary use of chemotherapy for low-risk patients with N0/N1 primary breast cancer is also the primary aim of the MINDACT and TAILORx trials (Rutgers et al. 2011; Zujewski \& Kamin 2008).

The aim of this study was to confirm a prognostic index based on the combination of proliferation (Ki67), histological grade, and ER (KiGE) in different subsets of chemo-naïve patients with N0/N1 primary breast cancer with special focus on five-year DDFS.

\section{Materials and methods Patients}

We included 1,854 women with primary breast cancer of which 1,522 originated from two randomized clinical studies (Patient materials I-II) and three cohorts (Patient materials III-V). The remaining 332 patients came from a case-control study (Patient material VI). Patients were excluded due to adjuvant chemotherapy and/or missing information on adjuvant therapy, Ki67, histological grade, or ER. Furthermore, for patients with more than three positive lymph nodes, adjuvant chemotherapy is recommended (as stated in the St. Gallen guidelines (Goldhirsch et al. 2011), hence these patients were also excluded. The endpoint for the 1,522 patients was defined as distant recurrence for $86 \%$ of the patients (Patient materials I-II and IV-V) and as any recurrence for the remaining 14\% (Patient material III). Time to this endpoint will hereafter be referred to as event-free survival. Median follow-up for patients alive and event-free at last follow-up was 7.2 years (range: 1.1-17 years). Only the first five years of follow-up were used in the analyses.

\section{Patient material I}

SBII:2-pre ( $N=221,68$ distant recurrences). Premenopausal women with stage II breast cancer were enrolled, between 1986 and 1991, in a randomized trial with the aim to compare the effect of two years of tamoxifen (TAM) treatment versus no adjuvant systemic treatment. The original trial included 564 patients enrolled in the South and South-East Swedish Health Care Regions (Rydén et al. 2005).

\section{Patient material II}

SBII:2-post ( $N=166,22$ distant recurrences). Postmenopausal women with stage II breast cancer were enrolled, between 1983 and 1991, in a randomized trial launched by the Swedish Breast Cancer group of two versus five years of adjuvant TAM (Swedish Breast Cancer Cooperative Group 1996). The original trial included 1,107 patients from the South Swedish Health Care Region. Paraffin embedded tumor material has previously been collected from a subgroup of patients treated with TAM for two years, for comparison of a cytosol method and immunohistochemistry for analyses of ER and PgR (Chebil et al. 2003). In the present study, the paraffin embedded material was used for analyses of Ki67 and HER2, and for the reevaluation of histological grade.

\section{Patient material III}

The Malmö cohort ( $N=217,32$ recurrences). The original cohort enrolled a consecutive series of 498 patients diagnosed with primary breast cancer at the Department of Pathology, Malmö University Hospital between 1988 and 1992. The purpose was to construct tissue microarrays for biomarker evaluation (Borgquist et al. 2008).

\section{Patient material IV}

The Bone marrow metastases cohort $(N=379,27$ distant recurrences). The original study included 569 consecutive 
patients diagnosed with primary breast cancer in the South Swedish Health Care Region and included patients diagnosed between 1999 and 2003. The purpose was to study the prognostic value of the presence of cytokeratin positive cells in bone marrow aspirates from the sternum (Falck et al. 2012).

\section{Patient material $V$}

The Odense cohort ( $N=539,86$ distant recurrences). The original study enrolled a consecutive series of 841 patients with primary breast cancer referred to Odense University Hospital, Denmark. Patients were enrolled between 1980 and 1990 (Hansen et al. 2000). The purpose was to collect a population-based cohort for evaluation of prognostic factors.

All patients from these collections (Patient materials $\mathrm{I}-\mathrm{V})$ were pooled in a database from which the following subsets were extracted: Set 1: node-negative (N0), no adjuvant therapy, $\leq 50$ years at diagnosis $(N=169,20$ events), Set 2: N0, no adjuvant therapy, $>50$ years at diagnosis ( $N=488,55$ events), Set 3: node-positive (N1), no adjuvant therapy ( $N=167,39$ events), Set 4: N0, adjuvant endocrine therapy $(N=291,39$ events), and Set 5: N1, adjuvant endocrine therapy $(N=407,82$ events $)$ (Table 1). The reason for the subdivision with regard to age between Sets 1 and 2 was to confirm the index from our original study (Strand et al. 2012) in a corresponding subgroup with regard to menopausal status, adjuvant therapy and lymph node status.

\section{Patient material VI}

The Uppsala study ( $N=166$ cases and 166 controls, Table 2). The original study included 900 patients diagnosed with primary breast cancer in the Uppsala-Örebro region from 1993-2004. Exclusion criteria were tumor size $>50 \mathrm{~mm}$, lymph node metastases or adjuvant chemotherapy. Within this cohort, cases were defined as women who died from breast cancer. Eligible as controls were patients alive at the time of the corresponding case's death (Ahlin et al. 2009).

\section{Biomarker analysis and definition of KiGE}

ER, PgR, Ki67, HER2, and histological grade were analyzed and evaluated as described elsewhere (Ahlin et al. 2009; Rydén et al. 2005; Chebil et al. 2003; Borgquist et al. 2008; Falck et al. 2012). If previously defined cutpoints were available, they were used in the present study. Hence, cases above the median were considered Ki67 high in Patient material V. Furthermore, Ahlin et al. defined high Ki67 as cases above the seventh decile of the empirical Ki67 distribution (which corresponded to $20 \%$ positive cells) (Klintman et al. 2010) and therefore $20 \%$ was used for Patient materials I-IV and VI. For Patient materials I-IV and VI, Ki67 was evaluated on
TMAs and for Patient material $\mathrm{V}$ on whole tissue sections. In order to confirm the combination of proliferation, histological grade, and ER, the previously applied index (CAGE) was used (Strand et al. 2012), but cyclin A was replaced by Ki67, thereby creating KiGE. The low KiGE-group was defined as histological grade 1 patients and grade 2 patients which were ER-positive and had low Ki67 expression. High KiGE consisted of all other patients.

\section{Statistical methods}

The Kaplan-Meier method was used to estimate eventfree survival and the Cox proportional hazards model, stratified by patient material, was used for estimation of hazard ratios (HR:s). Proportional hazards assumptions were checked with Schoenfeld's test (Schoenfeld 1983). To avoid severe problems with non-proportional hazards, the follow-up was restricted to the first five years after diagnosis.

In Patient material VI, conditional logistic regression analysis was used to estimate odds ratios (OR:s) and confidence intervals (CI:s), using the proportional hazards regression procedure in statistical analysis software (SAS).

Forest plots were used to visualize HR:s and 95\% CI:s for the different subsets and the overall measure of effect which was estimated using a DerSimonian-Laird random-effects model.

All tests were two-sided. For evaluation of the primary aim, the effect of the KiGE-index, $P$-values $<0.01$ were considered significant. The statistical analysis software Stata 12.1, 2012 (StataCorp, College Station, TX) and SAS (SAS Institute, Inc.) were used for statistical calculations. Whenever applicable, the REMARK recommendations for reporting of tumor marker studies were followed (McShane et al. 2005). The study was approved by the ethics committee at Lund University (LU 240-01).

\section{Results \\ KiGE evaluation \\ Univariate analyses}

The HR:s for high KiGE versus low KiGE, when each set (Set 1-5) was analyzed separately, varied between 3.0 and 4.4, being statistically significant for all sets (Figures 1a-e and 2a). When including all patients in Set $1-5(N=1,522,235$ events), a statistically significant association between the combination variable KiGE and event-free survival was found (HR: 3.9, 95\% CI: 2.9-5.2, $P<0.0001$; Figure 1f).

In the case-control study (Patient material VI), there was a statistically significant association between the combination variable KiGE and breast cancer death (OR: 2.7, 95\% CI: 1.7-4.3, $P<0.0001)$. 
Table 1 Patient and tumor characteristics

\begin{tabular}{|c|c|c|c|c|c|c|}
\hline Factor & Set 1 & Set 2 & Set 3 & Set 4 & Set 5 & Total \\
\hline No of patients & 169 & 488 & 167 & 291 & 407 & 1,522 \\
\hline Events & 20 & 55 & 39 & 39 & 82 & 235 \\
\hline Patient material I & 30 & 9 & 66 & 39 & 77 & 221 \\
\hline Patient material II & 0 & 0 & 0 & 67 & 99 & 166 \\
\hline Patient material III & 28 & 100 & 5 & 27 & 57 & 217 \\
\hline Patient material IV & 16 & 109 & 9 & 145 & 100 & 379 \\
\hline Patient material $V^{a}$ & 95 & 270 & 87 & 13 & 74 & 539 \\
\hline Age median, years & 45 & 65 & 53 & 61 & 61 & 60 \\
\hline Age range, years & $28-50$ & $50-90$ & $27-93$ & $30-88$ & $33-89$ & $27-93$ \\
\hline \multicolumn{7}{|l|}{ Tumor size } \\
\hline$\leq 20 \mathrm{~mm}$ & $113(67)^{\mathrm{b}}$ & $364(75)$ & $68(41)$ & $115(40)$ & $208(51)$ & $868(57)$ \\
\hline$>20 \mathrm{~mm}$ & $56(33)$ & $124(25)$ & $99(59)$ & $176(60)$ & $199(49)$ & $654(43)$ \\
\hline
\end{tabular}

Lymph nodes

$\begin{array}{lcccccc}\text { Negative } & 169 & 488 & 0 & 291 & 0 & 948(62) \\ 1-3 \text { positive } & 0 & 0 & 167 & 0 & 407 & 574(38)\end{array}$

ER status

$\begin{array}{lcccccc}\text { Positive } & 131(78) & 399(82) & 122(73) & 235(81) & 329(81) & 1,216(80) \\ \text { Negative } & 38(22) & 89(18) & 45(27) & 56(19) & 78(19) & 306(20)\end{array}$

PgR status

$\begin{array}{lcccccc}\text { Positive } & 46(71) & 121(61) & 56(70) & 168(63) & 200(63) & 591(64) \\ \text { Negative } & 19(29) & 76(39) & 24(30) & 100(37) & 118(37) & 337(36) \\ \text { Missing } & 104 & 291 & 87 & 23 & 89 & 594\end{array}$

Histological grade

$\begin{array}{lllllll}1 & 41(24) & 136(28) & 19(11) & 32(11) & 67(17) & 295(20) \\ 2 & 82(49) & 250(51) & 97(58) & 166(57) & 233(57) & 828(54) \\ 3 & 46(27) & 102(21) & 51(31) & 93(32) & 107(26) & 399(26)\end{array}$

Ki67

$\begin{array}{lcccccc}\text { Low } & 109(64) & 343(70) & 111(66) & 210(72) & 315(77) & 1,088(71) \\ \text { High }^{c} & 60(36) & 145(30) & 56(34) & 81(28) & 92(23) & 434(29)\end{array}$

HER2 status

$\begin{array}{lcccccc}\text { Negative } & 54(92) & 142(87) & 62(84) & 216(86) & 249(88) & 723(87) \\ \text { Positive }^{d} & 5(8) & 21(13) & 12(16) & 36(14) & 33(12) & 107(13) \\ \text { Missing } & 110 & 325 & 93 & 39 & 125 & 692\end{array}$

Adjuvant endocrine treatment

\begin{tabular}{|c|c|c|c|c|c|c|}
\hline Yes & 0 & 0 & 0 & 291 & 407 & $698(46)$ \\
\hline No & 169 & 488 & 167 & 0 & 0 & $824(54)$ \\
\hline
\end{tabular}

Patient materials I-V were pooled in a database from which the following subsets were extracted: Set 1: node-negative (N0), no adjuvant therapy, $\leq 50$ years at diagnosis, Set 2: N0, no adjuvant therapy, >50 years at diagnosis, Set 3: node-positive (N1), no adjuvant therapy, Set 4: N0, adjuvant endocrine therapy, and Set 5: $\mathrm{N} 1$, adjuvant endocrine therapy.

$E R=$ estrogen receptor, $P g R=$ progesterone receptor, $H E R 2$ = human epidermal growth factor 2.

a Patient material I (Rydén et al. 2005), Patient material II (Swedish Breast Cancer Cooperative Group 1996; Chebil et al. 2003), Patient material III (Borgquist et al. 2008), Patient material IV (Falck et al. 2012), and Patient material V (Hansen et al. 2000).

${ }^{\mathrm{b}}$ Numbers in parentheses are percentages.

${ }^{\mathrm{C}} \mathrm{High}$ Ki67 was previously defined as cases above the seventh decile in the empirical Ki67 distribution (which corresponds to $20 \%$ positive cells) (Klintman et al. 2010) and 20\% was used for Patient materials I-IV. Cases above the median were considered Ki67 high in Patient material V.

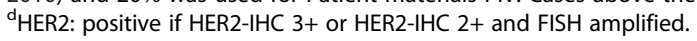




\section{Multivariate analyses}

The HR:s for KiGE for each of the five subsets, when adjusted for age at diagnosis and tumor size, were similar compared to those without adjustment, as illustrated by the forest plot (Figure 2b). When all subsets (Set 1-5) were included, KiGE was significantly associated with event-free survival, after adjustment for age at diagnosis, tumor size, and adjuvant endocrine treatment (HR: 3.5, 95\% CI: 2.6-4.7, $P<0.0001)$. Including HER2 in the multivariate analysis $(N=830,133$ events), KiGE remained

Table 2 Patient and tumor characteristics for the casecontrol study (Patient material VI (Ahlin et al. 2009)

\begin{tabular}{lcc}
\hline Factor & \multicolumn{2}{c}{ Patient material VI } \\
\cline { 2 - 3 } & Case & Control \\
\hline No of patients & 166 & 166 \\
Age median, years & 69 & 61 \\
Age range, years & $34-88$ & $32-89$
\end{tabular}

Tumor size

$\begin{array}{lcc}\leq 20 \mathrm{~mm} & 102(61)^{\mathrm{a}} & 131(79) \\ >20 \mathrm{~mm} & 64(39) & 35(21)\end{array}$

Lymph nodes

$\begin{array}{lll}\text { Negative } & 166 & 166\end{array}$

ER status

Positive $94(57) \quad 131(79)$

Negative $\quad 72(43) \quad 35(21)$

PgR status

$\begin{array}{lcc}\text { Positive } & 69(42) & 113(68) \\ \text { Negative } & 96(58) & 53(32) \\ \text { Missing } & 1 & 0\end{array}$

Histological grade

$\begin{array}{lll}1 & 14(8) & 39(23) \\ 2 & 85(51) & 94(57) \\ 3 & 67(41) & 33(20)\end{array}$

Ki67

$\begin{array}{lll}\text { Low } & 87(52) & 112(67) \\ \text { High }^{\mathrm{b}} & 79(48) & 54(33)\end{array}$

HER2 status

$\begin{array}{lcc}\text { Negative } & 145(91) & 143(92) \\ \text { Positive }^{c} & 14(9) & 13(8) \\ \text { Missing } & 7 & 10\end{array}$

Adjuvant endocrine treatment

$\begin{array}{lll}\text { Yes } & 48(29) & 40(24) \\ \text { No } & 118(71) & 126(76)\end{array}$

$E R=$ estrogen receptor, $P g R=$ progesterone receptor, $H E R 2=$ human epidermal growth factor 2 .

${ }^{a}$ Numbers in parentheses are percentages.

${ }^{\mathrm{b}} \mathrm{High} \mathrm{Ki} 67$ was defined as cases with more than $20 \%$ positive cells.

'HER2: positive if HER2-IHC 3+ or HER2-IHC 2+ and FISH amplified. significantly associated with event-free survival (HR: 4.0, 95\% CI: 2.7-6.0, $P<0.0001)$.

In the case-control study, KiGE was significantly associated with breast cancer death, after adjustment for age at diagnosis, tumor size, and adjuvant endocrine treatment (OR: 3.2, 95\% CI: $1.8-5.5, P<0.0001$ ).

\section{Subset analyses of Ki67 in patients not treated with adjuvant tamoxifen (Set 1-3)}

\section{Ki67 in ER-positive versus ER-negative cases}

In order to confirm results from previous investigations (Teschendorff et al. 2007; Desmedt et al. 2008; Klintman et al. 2010) showing that the prognostic importance of Ki67 is dependent on ER-status, subgroup analyses were performed, stratified by ER-status. In univariate analyses, Ki67 was a significant prognostic factor in the ER-positive subgroup (HR: 3.3, 95\% CI: 2.0-5.5, $P<0.0001 ; N=652,76$ events), but not in the ER-negative subgroup (HR: 1.0, 95\% CI: 0.49-2.1, $P=0.96 ; N=172,38$ events). The difference in prognostic importance of Ki67 between ER-positive and ER-negative cases was further analyzed in a Cox model allowing for interaction between the two factors. The interaction effect, corresponding to the ratio of the HR:s for Ki67 in the ER-positive and ER-negative subgroups, was 2.7 (95\% CI: 1.2-6.1, $P=0.02)$.

\section{Ki67 in histological grade subgroups}

Previous studies have demonstrated that the prognostic importance of Ki67 is mainly attributed to the histological grade 2 subgroup (Klintman et al. 2010; Aleskandarany et al. 2011). Similar trends were seen in the present study. In the histological grade 2 tumors ( $N=429,51$ events), the HR for high versus low Ki67 was 1.8 (95\% CI: 1.0-3.4, $P=0.05$ ). The five-year event-free survival figures were $82 \%$ (95\% CI: 73-88\%) for high Ki67 and 90\% (95\% CI: 86-93\%) for low Ki67, respectively. There were too few events ( $N=196,5$ events) to draw any conclusions on the impact of Ki67 in the histological grade 1 subgroup. The five-year event-free survival in the histological grade 1 subgroup was 97\% (95\% CI: 93-99\%), independent of Ki67. Ki67 was not a significant prognostic factor in the histological grade 3 subgroup (HR: 1.0, 95\% CI: 0.56-1.9, $P=0.91 ; N=199,58$ events), with five-year DDFS of $73 \%$ (95\% CI: 64-79\%) and $65 \%$ (95\% CI: 52-76\%) for high and low Ki67 groups, respectively.

\section{Five-year DDFS for high and low KiGE (Patient materials} I-II and IV-V)

Use of the KiGE-index in the N0/N1-subgroup with information on distant recurrences $(N=1,305,203$ distant recurrences) identified a low-risk group 


\section{a)}

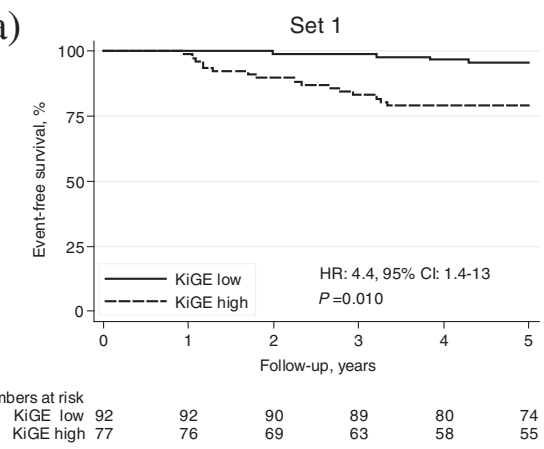

c)

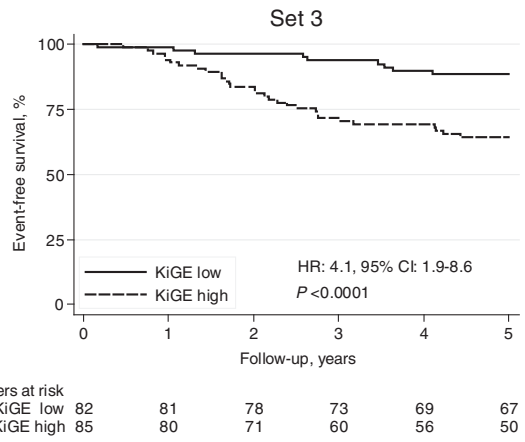

e)

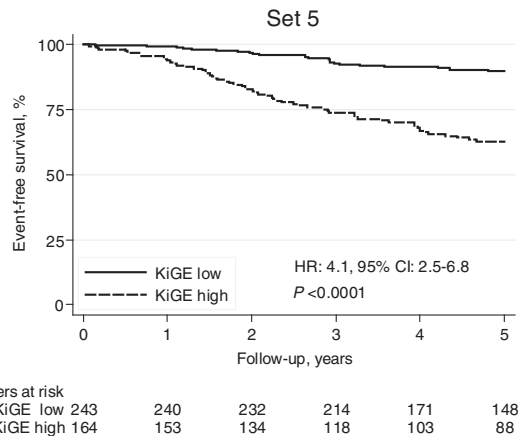

b)

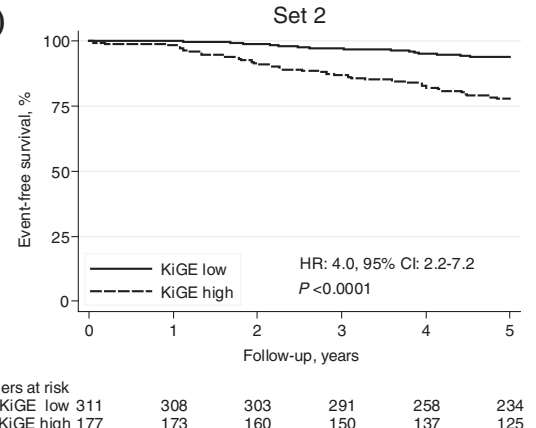

d)

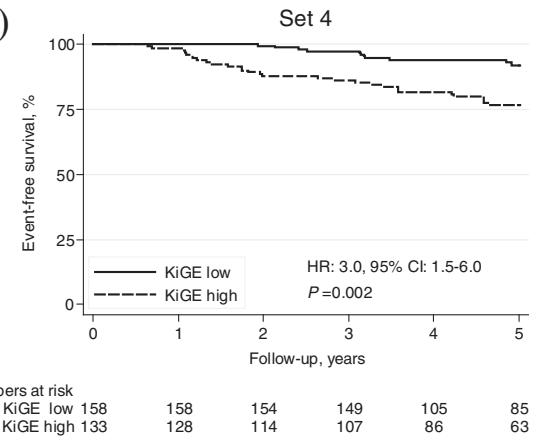

f)

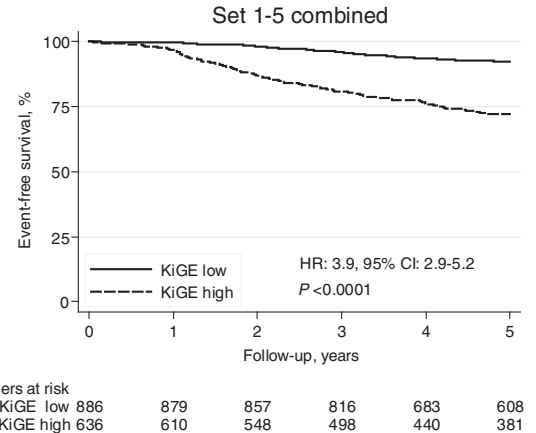

Figure 1 Kaplan-Meier survival estimates of event-free survival, and hazard ratios (HR) with corresponding $95 \%$ confidence intervals (CI) for the different subsets (1a-e), stratified by patient material, and for all the patients (1f). From Patient materials I-V the following subsets were extracted: Set 1: node-negative (N0), no adjuvant therapy, $\leq 50$ years at diagnosis (1a), Set 2: N0, no adjuvant therapy, $>50$ years at diagnosis (1 b), Set 3: node-positive (N1), no adjuvant therapy (1c), Set 4: N0, adjuvant endocrine therapy (1d), and Set 5: N1, adjuvant endocrine therapy (1e). Event-free survival corresponds to distant disease-free survival for Patient materials I-II and IV-V, and to recurrence-free survival for Patient material III.

constituting $57 \%$ of the patients, with a five-year DDFS of $92 \%$ (95\% CI: $89-93 \%)$. The DDFS for the remaining $43 \%$ of the patients was $73 \%$ (95\% CI: $69-$ 77\%). The association between the KiGE-index and DDFS was statistically significant (HR: $3.4,95 \%$ CI: 2.5-4.6, $P<0.0001$; Figure 3).

In the N0-subgroup ( $N=793,97$ distant recurrences), the KiGE-index identified a low-risk group constituting $57 \%$ of the patients with a five-year DDFS of $93 \%$ (95\% CI: 90-95\%; HR: 3.2, 95\% CI: 2.0-4.9, $P<0.0001)$. Equally, in the N1-subgroup ( $N=512,106$ distant recurrences), the KiGE-index identified a low-risk group of similar size (56\%) with a five-year DDFS of $89 \%$ (95\% CI: 85-92\%; HR: 3.7, 95\% CI: 2.4-5.7, $P<0.0001)$.

\section{Discussion}

This confirmation study for N0/N1 chemo-naïve breast cancer patients, confirms the prognostic value of a previously defined index combining proliferation (previously cyclin A, in the present study Ki67), histological grade, and ER. Importantly, the KiGE-index separated chemonaïve patients into groups with different risk, independent of menopausal status, lymph node status, and whether endocrine adjuvant treatment was given or not. The robustness of the index is strengthened by the fact that the evaluation of Ki67, histological grade, and ER was performed in different studies by different persons using different cut-points, that studies from three Swedish health care regions and one Danish region were 
a)

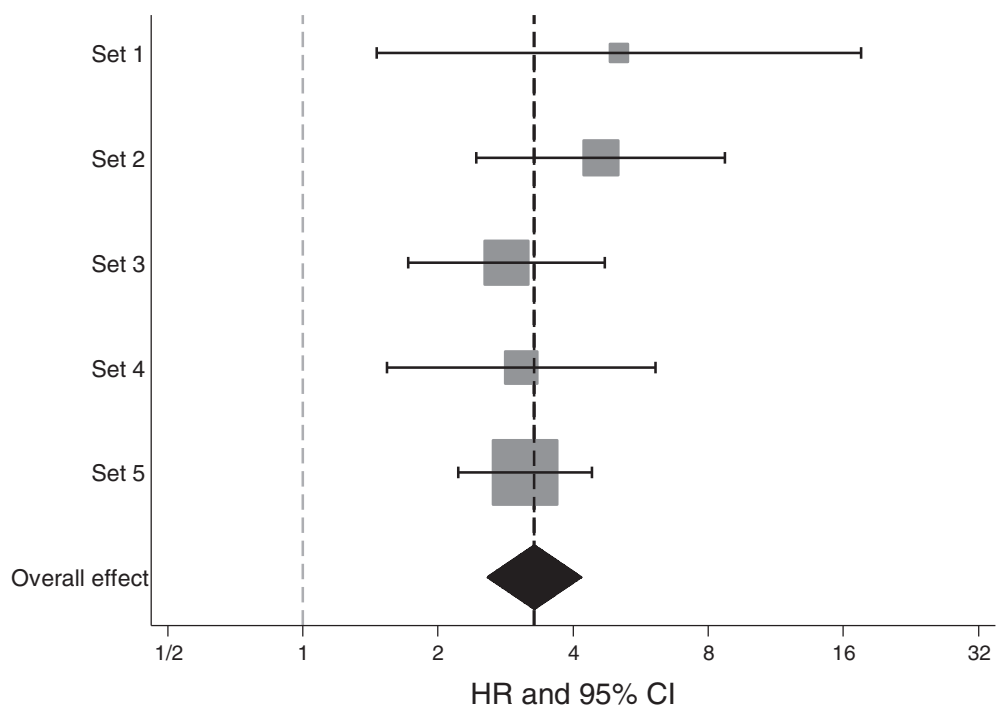

b)

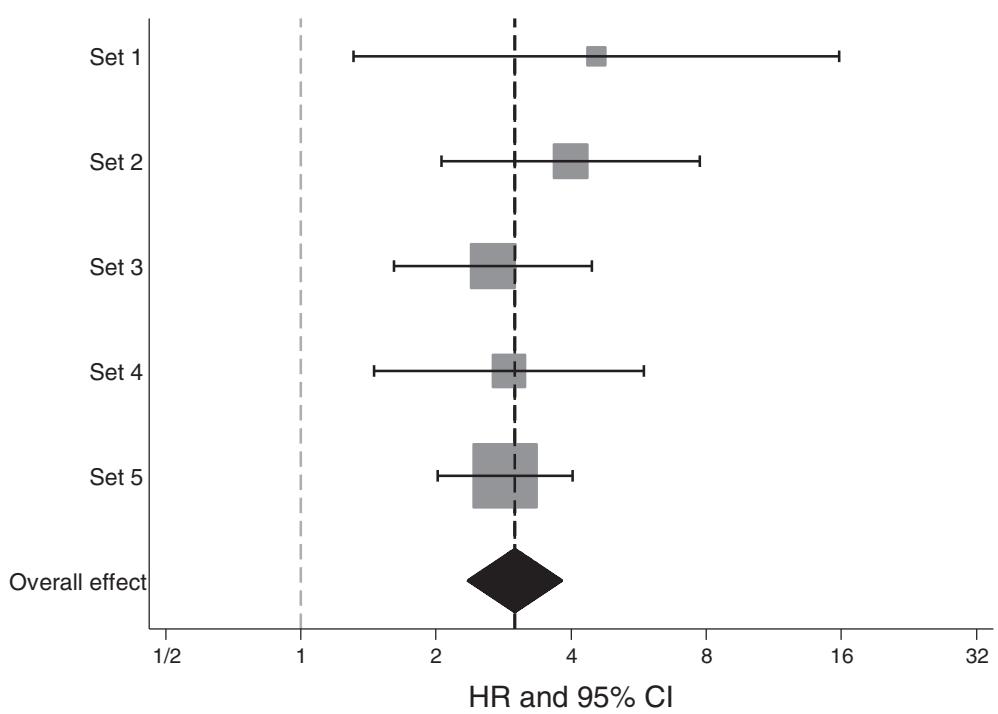

Figure 2 Forest plots for the different subsets, showing hazard ratios (HR:s) with corresponding 95\% confidence intervals (Cl:s) for KiGE in univariate analysis (a) and in multivariate analysis (b), adjusted for age at diagnosis and tumor size. The diamonds and the vertical dashed lines represent the overall measures of effect. The areas of the grey squares are proportional to each subset's weight in the meta-analysis.

included, and by the fact that different study designs were used (randomized, cohort and case-control studies). Furthermore, when analyzing Patient materials I-V separately (not the five sets), KiGE remained a significant prognostic factor (HR:s varied between 2.1 and 9.0) in all but one patient material (Patient material II, $P=0.09$; data not shown). We were also able to confirm the previous finding that the prognostic value of Ki67 is limited to ER-positive breast cancer and is most pronounced for the histological grade 2 subgroup. The latter findings are furthermore in line with gene expression analyses (Sotiriou et al. 2006; Ivshina et al. 2006; Teschendorff et al. 2007; Desmedt et al. 2008). However, a recent publication (Munzone et al. 2012) showed that within the group of patients with nodenegative triple-negative breast cancer, Ki67 was associated with different prognosis when using a higher cut-point (35\%). The KiGE-index is similar to the index proposed at the St. Gallen consensus meeting in 2011 (Goldhirsch et al. 2011), with Ki67 separating clinicopathologically classified 'Luminal' ER-positive breast cancer into 'Luminal A' and 'Luminal B' subgroups with 


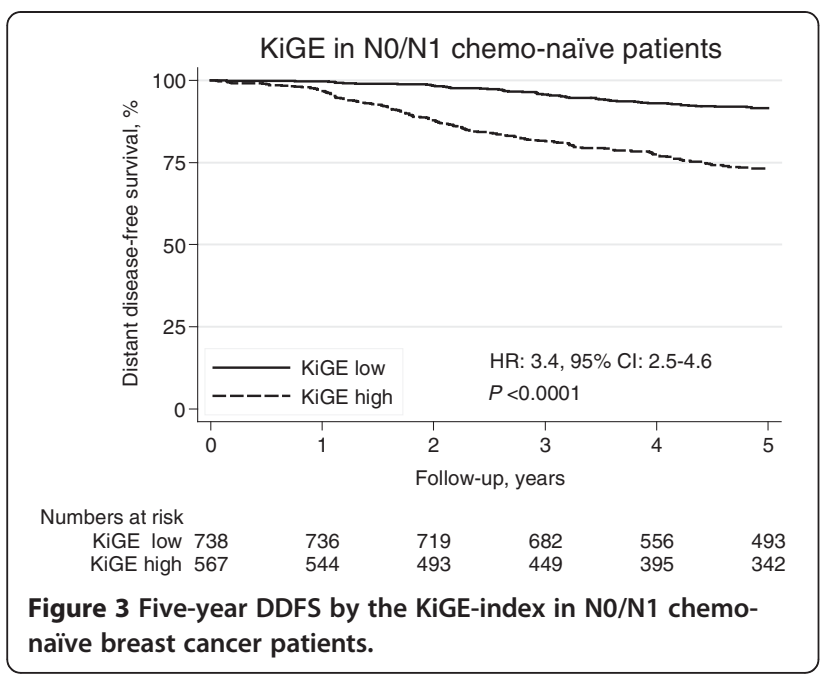

different prognoses and thereby influence on the choice of therapy. Chemotherapy, with or without anti-HER2 therapy, is suggested for the 'Luminal B' subgroup, but not for the 'Luminal A' subgroup (Goldhirsch et al. 2011). According to the St. Gallen guidelines, not taking histological grade into consideration, patients with ERpositive low proliferating (and HER2 normal) tumors will be classified as having 'Luminal A' breast cancer. According to the KiGE-index, with the inclusion of histological grade, some of these patients will instead be considered as having worse prognosis. In this large patient material, patients with ER-positive, low Ki67, and histological 3 breast cancer $(N=42)$ have a poor prognosis, with a five-year DDFS of 64\% (95\% CI: 47-76\%). This subgroup constituted 6\% (42/652) of the ERpositive (chemo-naïve) patients in our study (Patient materials $\mathrm{I}-\mathrm{V}$ ). In a recent publication by the International Ki67 in Breast Cancer Working Group (Dowsett et al. 2011), certain important drawbacks for Ki67 analyses were highlighted, including number of cancer cells being scored and cut-point used. Furthermore, the distribution of Ki67 values makes it difficult to define a cut-point. The inherent drawbacks with the evaluation of Ki67 may at least partly be overcome by also considering histological grade, as suggested in the present study. Our study was, probably due to low power, unable to demonstrate any prognostic importance of Ki67 in histological grade 1 breast cancer. Aleskandarany et al. however, demonstrated that patients with high Ki67 had a significantly worse prognosis than those with low Ki67, in a large study, including 494 histological grade 1 breast cancers (Aleskandarany et al. 2011). Therefore, we do not exclude the possibility that Ki67 has prognostic value in the histological grade 1 subgroup.

Identifying a subgroup of patients not in need of adjuvant chemotherapy, was found to be the top priority on a list of the most urgent research areas in breast cancer in a recent web-consultant study (Dowsett et al. 2007). The Early Breast Cancer Trialists' Collaborative Group (Peto et al. 2012) demonstrated that the effect of chemotherapy was independent of age, node status, tumor size, differentiation, ER-status, and tamoxifen use. However, information on quantitative immunohistochemistry of proliferation was not included. Ki67 combined with ER-status and histological grade may be helpful in this respect. Breast cancer patients with histological grade 1 tumors or patients with ER-positive and histological grade 2 tumors with low Ki67 expression constitute 57\% of the patients with N0/N1 cancers in this study, with a five-year DDFS of 92\%. Adjuvant chemotherapy would have limited added value for this group. The identification of a low-risk group not in need of adjuvant chemotherapy is also the primary aim of two ongoing clinical trials (MINDACT and TAILORx) (Rutgers et al. 2011; Zujewski \& Kamin 2008) evaluating the gene profiles MammaPrint ${ }^{\circledR}$ and OncotypeDX ${ }^{\circledR}$. The MINDACT trial (Rutgers et al. 2011) is a prospective, randomized trial using the 70-gene signature (MammaPrint ${ }^{\circledR}$ ) together with the common clinical-pathological criteria for selecting patients for adjuvant chemotherapy. It is being tested in patients with N0/N1 breast cancer. MINDACT has a null hypothesis of a five-year distant metastasisfree survival of $92 \%$, which will be tested for the group of patients who have a low-risk gene prognosis signature and high clinical-pathological criteria, and who were randomized to use the 70-gene signature and thus receive no chemotherapy. In a pilot phase based on the first 800 patients from this trial, the low-risk group constituted 65\% (Rutgers et al. 2011). This figure is in line with $57 \%$ being the percentage of low-risk patients in our study, who furthermore had the same five-year DDFS as the null hypothesis in the MINDACT trial (92\%). Risk group stratification may be further modified by also considering other established prognostic factors, e.g. lymph node status, tumor size, age, and HER2status. The incidence of recurrences in the low-risk group could thereby be further decreased, but with the consequence of a smaller low-risk group.

In conclusion, we have confirmed a prognostic index based on proliferation (Ki67), histological grade, and ER for identifying a low-risk group of patients with N0/N1 breast cancer. For this large low-risk group, with a five-year DDFS of 92\%, adjuvant chemotherapy will have limited effect and may thus be avoided.

\section{Competing interest}

The authors have no conflicts of interest to declare.

\section{Authors' contributions}

CS, MK, POB, PM and MF were responsible for concept and design of the study. Financial and administrative support was provided by MF. MB, SB, GC, AKF, MLF, DG, KJ, MK, PM, HO, LR and OS provided study material and 
information of patients. CS, DG, $\mathrm{H}, \mathrm{PM}, \mathrm{POB}$ and MF were responsible of data analysis and interpretation. CS, MF and POB were responsible for the manuscript writing. All authors read and approved the final version of the manuscript.

\section{Acknowledgments}

We are indebted to participating departments of the South and South-East Swedish Breast Cancer Groups, of the Uppsala-Örebro region, and of the Odense region for providing samples and clinical follow-up. We thank Kristina Lövgren for technical skills in creating the TMA blocks and Marit Holmqvist for statistical analysis of the case-control study.

\section{Funding}

This work was supported by funding from the Swedish Cancer Society, the Swedish Research Council, the Gunnar Nilsson Cancer Foundation, the Mrs. Berta Kamprad Foundation, the Anna and Edwin Bergers foundation, the Swedish Breast Cancer Association (BRO), the Skåne University Hospital Research Foundation, the Skåne County Council's Research and Development Foundation, and Governmental Funding of Clinical Research within the National Health Service.

\section{Author details}

${ }^{1}$ Lund University, Division of Oncology, Department of Clinical Sciences Lund, Skåne University Hospital, Barngatan 2B, SE-221 85, Lund, Sweden. ${ }^{2}$ Department of Pathology, Odense University Hospital, DK-5000, Odense, Denmark. ${ }^{3}$ Unilabs, Mammography, Bergaliden SE-252 23, Helsingborg, Sweden. ${ }^{4}$ Department of Surgery, Helsingborg Hospital, SE-281 85, Helsingborg, Sweden. ' Uppsala University, Department of Oncology, Radiology and Clinical Immunology, SE-751 85, Uppsala, Sweden. 'Lund University, Department of Pathology, Skåne University Hospital, SE-221 85, Lund, Sweden. 'Division of Pathology, Department of Clinical Sciences Lund, Lund University, SE-221 85, Lund, Sweden. ${ }^{8}$ Skåne Department of Oncology, Skåne University Hospital, SE-221 85, Lund, Sweden. ${ }^{9}$ Department of Clinical and Experimental Medicine, Faculty of Health Sciences, Department of Clinical Pathology and Clinical Genetics, County Council of Östergötland, Linköping University, Molecular and Immunological Pathology, SE-581 91, Linköping, Sweden. ${ }^{10}$ Lund University, Division of Surgery, Department of Clinical Sciences Lund, Skåne University Hospital, SE-221 85, Lund, Sweden.

${ }^{11}$ Linköping University, Division of Oncology, Department of Clinical and Experimental Medicine, Faculty of Health Sciences, County Council of Östergötland, SE-581 85, Linköping, Sweden.

\section{Received: 28 February 2013 Accepted: 4 March 2013} Published: 14 March 2013

\section{References}

Aebi S, Davidson T, Gruber G, Cardoso F (2011) Primary breast cancer: ESMO Clinical Practice Guidelines for diagnosis, treatment and follow-up. Ann Oncol Offic J Eur Soc Med Oncol/ESMO 22(Suppl 6):vi12-24.

Ahlin C, Zhou W, Holmqvist M, Holmberg L, Nilsson C, Jirstrom K, Blomqvist C, Amini RM, Fjallskog ML (2009) Cyclin A is a proliferative marker with good prognostic value in node-negative breast cancer. Canc Epidemiol Biomark Prev Publ Am Assoc Canc Res Cosponsored Am Soc Prev Oncol 18(9):25012506.

Aleskandarany MA, Rakha EA, Macmillan RD, Powe DG, Ellis IO, Green AR (2011) $\mathrm{MIB1} / \mathrm{Ki}-67$ labelling index can classify grade 2 breast cancer into two clinically distinct subgroups. Breast Cancer Res Treat 127(3):591-599.

Amadori D, Nanni O, Volpi A, Casadei Giunchi D, Marangolo M, Livi L, Ravaioli A, Rossi AP, Gambi A, Luzi Fedeli S, Perroni D, Scarpi E, Becciolini A, Silvestrini R (2008) Phase III randomized multicenter study on the effects of adjuvant CMF in patients with node-negative, rapidly proliferating breast cancer: twelve-year results and retrospective subgroup analysis. Breast Cancer Res Treat 108(2):259-264.

Baldini E, Camerini A, Sgambato A, Prochilo T, Capodanno A, Pasqualetti F, Orlandini C, Resta L, Bevilacqua G, Collecchi P (2006) Cyclin A and E2F1 overexpression correlate with reduced disease-free survival in node-negative breast cancer patients. Anticancer Res 26(6B):4415-4421.

Beresford MJ, Wilson GD, Makris A (2006) Measuring proliferation in breast cancer: practicalities and applications. Breast Cancer Res 8(6):216.

Borgquist S, Holm C, Stendahl M, Anagnostaki L, Landberg G, Jirstrom K (2008) Oestrogen receptors alpha and beta show different associations to clinicopathological parameters and their co-expression might predict a better response to endocrine treatment in breast cancer. J Clin Pathol 61(2):197-203.

Bukholm IR, Bukholm G, Nesland JM (2001) Over-expression of cyclin A is highly associated with early relapse and reduced survival in patients with primary breast carcinomas. Int J Canc J Int Canc 93(2):283-287.

Chebil G, Bendahl PO, Idvall I, Ferno M (2003) Comparison of immunohistochemical and biochemical assay of steroid receptors in primary breast cancer-clinical associations and reasons for discrepancies. Acta Oncol 42(7):719-725.

Colozza M, Azambuja E, Cardoso F, Sotiriou C, Larsimont D, Piccart MJ (2005) Proliferative markers as prognostic and predictive tools in early breast cancer: where are we now? Ann Oncol 16(11):1723-1739.

Cuzick J, Dowsett M, Pineda S, Wale C, Salter J, Quinn E, Zabaglo L, Mallon E, Green AR, Ellis IO, Howell A, Buzdar AU, Forbes JF (2011) Prognostic value of a combined estrogen receptor, progesterone receptor, Ki-67, and human epidermal growth factor receptor 2 immunohistochemical score and comparison with the Genomic Health recurrence score in early breast cancer. J Clin Oncol 29(32):4273-4278.

De Azambuja E, Cardoso F, de Castro G Jr, Colozza M, Mano MS, Durbecq V, Sotiriou C, Larsimont D, Piccart-Gebhart MJ, Paesmans M (2007) Ki-67 as prognostic marker in early breast cancer: a meta-analysis of published studies involving 12,155 patients. Br J Cancer 96(10):1504-1513.

Desmedt C, Haibe-Kains B, Wirapati P, Buyse M, Larsimont D, Bontempi G, Delorenzi M, Piccart M, Sotiriou C (2008) Biological processes associated with breast cancer clinical outcome depend on the molecular subtypes. Clin Cancer Res 14(16):51585165.

Dowsett M, Goldhirsch A, Hayes DF, Senn HJ, Wood W, Viale G (2007) International Web-based consultation on priorities for translational breast cancer research. Breast Cancer Res 9(6):81.

Dowsett M, Nielsen TO, A'Hern R, Bartlett J, Coombes RC, Cuzick J, Ellis M, Henry NL, Hugh JC, Lively T, McShane L, Paik S, Penault-Llorca F, Prudkin L, Regan M, Salter J, Sotiriou C, Smith IE, Viale G, Zujewski JA, Hayes DF (2011) Assessment of Ki67 in breast cancer: recommendations from the International Ki67 in Breast Cancer working group. J Natl Cancer Inst 103(22):1656-1664.

Eden P, Ritz C, Rose C, Ferno M, Peterson C (2004) "Good Old" clinical markers have similar power in breast cancer prognosis as microarray gene expression profilers. Eur J Cancer 40(12):1837-1841.

Ellis MJ, Tao Y, Luo J, A'Hern R, Evans DB, Bhatnagar AS, Chaudri Ross HA, von Kameke A, Miller WR, Smith I, Eiermann W, Dowsett M (2008) Outcome prediction for estrogen receptor-positive breast cancer based on postneoadjuvant endocrine therapy tumor characteristics. J Natl Cancer Inst 100(19):1380-1388.

Falck AK, Bendahl PO, Ingvar C, Isola J, Jonsson PE, Lindblom P, Lovgren K, Rennstam K, Ferno M, Rydén L (2012) Analysis of and prognostic information from disseminated tumour cells in bone marrow in primary breast cancer: a prospective observational study. BMC Cancer 12(1):403.

Goldhirsch A, Ingle JN, Gelber RD, Coates AS, Thurlimann B, Senn HJ (2009) Thresholds for therapies: highlights of the St Gallen International Expert Consensus on the primary therapy of early breast cancer 2009. Ann Oncol 20(8):1319-1329.

Goldhirsch A, Wood WC, Coates AS, Gelber RD, Thurlimann B, Senn HJ (2011) Strategies for subtypes--dealing with the diversity of breast cancer: highlights of the St Gallen International Expert Consensus on the Primary Therapy of Early Breast Cancer 2011. Ann Oncol 22(8):1736-1747.

Hansen S, Grabau DA, Sorensen FB, Bak M, Vach W, Rose C (2000) The prognostic value of angiogenesis by Chalkley counting in a confirmatory study design on 836 breast cancer patients. Clin Canc Res Offic J Am Assoc Canc Res 6(1):139-146.

Harris L, Fritsche H, Mennel R, Norton L, Ravdin P, Taube S, Somerfield MR, Hayes DF, Bast RC Jr (2007) American Society of Clinical Oncology 2007 update of recommendations for the use of tumor markers in breast cancer. J Clin Oncol 25(33):5287-5312.

Hietanen P, Blomqvist C, Wasenius VM, Niskanen E, Franssila K, Nordling S (1995) Do DNA ploidy and $\mathrm{S}$-phase fraction in primary tumour predict the response to chemotherapy in metastatic breast cancer? Br J Cancer 71(5):1029-1032.

Ivshina AV, George J, Senko O, Mow B, Putti TC, Smeds J, Lindahl T, Pawitan Y, Hall P, Nordgren H, Wong JE, Liu ET, Bergh J, Kuznetsov VA, Miller LD (2006) Genetic reclassification of histologic grade delineates new clinical subtypes of breast cancer. Cancer Res 66(21):10292-10301. 
Jones RL, Salter J, A'Hern R, Nerurkar A, Parton M, Reis-Filho JS, Smith IE, Dowsett M (2009) The prognostic significance of Ki67 before and after neoadjuvant chemotherapy in breast cancer. Breast Cancer Res Treat 116(1):53-68.

Klintman M, Bendahl PO, Grabau D, Lovgren K, Malmstrom P, Ferno M (2010) The prognostic value of Ki67 is dependent on estrogen receptor status and histological grade in premenopausal patients with node-negative breast cancer. Mod Pathol 23(2):251-259.

Kuhling $\mathrm{H}$, Alm P, Olsson H, Ferno M, Baldetorp B, Parwaresch R, Rudolph P (2003) Expression of cyclins $E, A$, and B, and prognosis in lymph nodenegative breast cancer. J Pathol 199(4):424-431.

Luporsi E, Andre F, Spyratos F, Martin PM, Jacquemier J, Penault-Llorca F, Tubiana-Mathieu N, Sigal-Zafrani B, Arnould L, Gompel A, Egele C, Poulet B, Clough KB, Crouet H, Fourquet A, Lefranc JP, Mathelin C, Rouyer N, Serin D, Spielmann M, Haugh M, Chenard MP, Brain E, de Cremoux P, Bellocq JP (2012) Ki-67: level of evidence and methodological considerations for its role in the clinical management of breast cancer: analytical and critical review. Breast Cancer Res Treat 132(3):895-915

McShane LM, Altman DG, Sauerbrei W, Taube SE, Gion M, Clark GM (2005) Reporting recommendations for tumor marker prognostic studies (REMARK) J Natl Cancer Inst 97(16):1180-1184.

Michalides R, van Tinteren H, Balkenende A, Vermorken JB, Benraadt J, Huldij J, van Diest $P$ (2002) Cyclin $A$ is a prognostic indicator in early stage breast cancer with and without tamoxifen treatment. Br J Cancer 86(3):402-408.

Munzone E, Botteri E, Sciandivasci A, Curigliano G, Nole F, Mastropasqua M, Rotmensz N, Colleoni M, Esposito A, Adamoli L, Luini A, Goldhirsch A, Viale G (2012) Prognostic value of Ki-67 labeling index in patients with nodenegative, triple-negative breast cancer. Breast Cancer Res Treat 134(1): 277-282.

Paik S, Shak S, Tang G, Kim C, Baker J, Cronin M, Baehner FL, Walker MG, Watson D, Park T, Hiller W, Fisher ER, Wickerham DL, Bryant J, Wolmark N (2004) A multigene assay to predict recurrence of tamoxifen-treated, node-negative breast cancer. N Eng J Med 351(27):2817-2826.

Perou CM, Sorlie T, Eisen MB, van de Rijn M, Jeffrey SS, Rees CA, Pollack JR, Ross DT, Johnsen H, Akslen LA, Fluge O, Pergamenschikov A, Williams C, Zhu SX, Lonning PE, Borresen-Dale AL, Brown PO, Botstein D (2000) Molecular portraits of human breast tumours. Nature 406(6797):747-752.

Peto R, Davies C, Godwin J, Gray R, Pan HC, Clarke M, Cutter D, Darby S, McGale P, Taylor C, Wang YC, Bergh J, Di Leo A, Albain K, Swain S, Piccart M, Pritchard K (2012) Comparisons between different polychemotherapy regimens for early breast cancer: meta-analyses of long-term outcome among 100,000 women in 123 randomised trials. Lancet 379(9814):432-444

Ravdin PM, Siminoff LA, Davis GJ, Mercer MB, Hewlett J, Gerson N, Parker HL (2001) Computer program to assist in making decisions about adjuvant therapy for women with early breast cancer. J Clin Oncol 19(4):980-991

Rutgers E, Piccart-Gebhart MJ, Bogaerts J, Delaloge S, Veer LV, Rubio IT, Viale G, Thompson AM, Passalacqua R, Nitz U, Vindevoghel A, Pierga JY, Ravdin PM, Werutsky G, Cardoso F (2011) The EORTC 10041/BIG 03-04 MINDACT trial is feasible: results of the pilot phase. Eur J Cancer 47(18):2742-2749.

Rydén L, Jonsson PE, Chebil G, Dufmats M, Ferno M, Jirstrom K, Kallstrom AC, Landberg G, Stal O, Thorstenson S, Nordenskjold B (2005) Two years of adjuvant tamoxifen in premenopausal patients with breast cancer: a randomised, controlled trial with long-term follow-up. Eur J Cancer $41(2): 256-264$.

Schoenfeld DA (1983) Sample-size formula for the proportional-hazards regression model. Biometrics 39(2):499-503.

Skaland I, Janssen EA, Gudlaugsson E, Klos J, Kjellevold KH, Soiland H, Baak JP (2007) Phosphohistone H3 expression has much stronger prognostic value than classical prognosticators in invasive lymph node-negative breast cancer patients less than 55 years of age. Mod Pathol 20(12):1307-1315.

Sorlie T, Perou CM, Tibshirani R, Aas T, Geisler S, Johnsen H, Hastie T, Eisen MB, van de Rijn M, Jeffrey SS, Thorsen T, Quist H, Matese JC, Brown PO, Botstein D, Eystein Lonning P, Borresen-Dale AL (2001) Gene expression patterns of breast carcinomas distinguish tumor subclasses with clinical implications. Proc Natl Acad Sci USA 98(19):10869-10874.

Sotiriou C, Wirapati P, Loi S, Harris A, Fox S, Smeds J, Nordgren H, Farmer P, Praz V, Haibe-Kains B, Desmedt C, Larsimont D, Cardoso F, Peterse H, Nuyten D, Buyse M, Van de Vijver MJ, Bergh J, Piccart M, Delorenzi M (2006) Gene expression profiling in breast cancer: understanding the molecular basis of histologic grade to improve prognosis. J Natl Cancer Inst 98(4):262-272.

Strand C, Ahlin C, Bendahl PO, Fjallskog ML, Hedenfalk I, Malmstrom P, Ferno M (2012) Combination of the proliferation marker cyclin A, histological grade, and estrogen receptor status in a new variable with high prognostic impact in breast cancer. Breast Cancer Res Treat 131(1):33-40.

Swedish Breast Cancer Cooperative Group (1996) Randomized trial of two versus five years of adjuvant tamoxifen for postmenopausal early stage breast cancer. Swedish Breast Cancer Cooperative Group. J Natl Cancer Inst 88 (21):1543-1549.

Teschendorff AE, Miremadi A, Pinder SE, Ellis IO, Caldas C (2007) An immune response gene expression module identifies a good prognosis subtype in estrogen receptor negative breast cancer. Genome Biol 8(8):157.

Urruticoechea A, Smith IE, Dowsett M (2005) Proliferation marker Ki-67 in early breast cancer. J Clin Oncol 23(28):7212-7220.

Viale G, Regan MM, Mastropasqua MG, Maffini F, Maiorano E, Colleoni M, Price KN, Golouh R, Perin T, Brown RW, Kovacs A, Pillay K, Ohlschlegel C, Gusterson BA, Castiglione-Gertsch M, Gelber RD, Goldhirsch A, Coates AS (2008) Predictive value of tumor Ki-67 expression in two randomized trials of adjuvant chemoendocrine therapy for node-negative breast cancer. J Natl Cancer Inst 100(3):207-212.

Zujewski JA, Kamin L (2008) Trial assessing individualized options for treatment for breast cancer: the TAILORx trial. Future Oncol 4(5):603-610.

doi:10.1186/2193-1801-2-111

Cite this article as: Strand et al:: The combination of Ki67, histological grade and estrogen receptor status identifies a low-risk group among 1,854 chemo-naïve women with N0/N1 primary breast cancer. SpringerPlus 2013 2:111.

\section{Submit your manuscript to a SpringerOpen ${ }^{\odot}$ journal and benefit from:}

- Convenient online submission

Rigorous peer review

- Immediate publication on acceptance

- Open access: articles freely available online

- High visibility within the field

- Retaining the copyright to your article

Submit your next manuscript at $>$ springeropen.com 